\title{
Spinal cord injury below-level neuropathic pain relief with dorsal root entry zone microcoagulation performed caudal to level of complete spinal cord transection
}

\author{
Scott Falci, MD, ${ }^{1}$ Charlotte Indeck, MSN, ${ }^{1}$ and Dave Barnkow, AuD ${ }^{2}$ \\ ${ }^{1}$ Neurosurgery, Craig Hospital, Englewood; and 2Medsurant, LLC, Englewood, Colorado
}

OBJECTIVE Surgically created lesions of the spinal cord dorsal root entry zone (DREZ) to relieve central pain after spinal cord injury (SCI) have historically been performed at and cephalad to, but not below, the level of SCl. This study was initiated to investigate the validity of 3 proposed concepts regarding the DREZ in SCI central pain: 1) The spinal cord DREZ caudal to the level of $\mathrm{SCl}$ can be a primary generator of $\mathrm{SCl}$ below-level central pain. 2) Neuronal transmission from a DREZ that generates $\mathrm{SCl}$ below-level central pain to brain pain centers can be primarily through sympathetic nervous system (SNS) pathways. 3) Perceived SCI below-level central pain follows a unique somatotopic map of DREZ pain-generators.

METHODS Three unique patients with both intractable SCI below-level central pain and complete spinal cord transection at the level of $\mathrm{SCl}$ were identified. All 3 patients had previously undergone surgical intervention to their spinal cords - only cephalad to the level of spinal cord transection - with either DREZ microcoagulation or cyst shunting, in failed attempts to relieve their SCI below-level central pain. Subsequent to these surgeries, DREZ lesioning of the spinal cord solely caudal to the level of complete spinal cord transection was performed using electrical intramedullary guidance. The follow-up period ranged from 11/2 to 11 years.

RESULTS All 3 patients in this study had complete or near-complete relief of all below-level neuropathic pain. The analyzed electrical data confirmed and enhanced a previously proposed somatotopic map of SCI below-level DREZ pain generators.

CONCLUSIONS The results of this study support the following hypotheses. 1) The spinal cord DREZ caudal to the level of $\mathrm{SCl}$ can be a primary generator of $\mathrm{SCl}$ below-level central pain. 2) Neuronal transmission from a DREZ that generates SCI below-level central pain to brain pain centers can be primarily through SNS pathways. 3) Perceived SCI below-level central pain follows a unique somatotopic map of DREZ pain generators.

https://thejns.org/doi/abs/10.3171/2017.9.SPINE17373

KEY WORDS spinal cord injury; neuropathic pain; dorsal root entry zone; central pain

卫 HE prevalence of severe or disabling chronic pain after spinal cord injury (SCI) ranges from $20 \%$ to $77 \% ., 2,15,18,19,21$ These pains are believed to be of central origin and have been termed central deafferentation pains. ${ }^{510,11,22}$ They always occur in regions of anesthesia or hypesthesia, and the most common pain descriptors include burning, sharp, electrical, stabbing, and pins-andneedles sensations. SCI central pain can be perceived at the dermatomal level of injury (at-level pain) or at dermatomal levels below the level of injury (below-level pain), or it can be perceived as both at-level and below-level pain. Pharmacological management of these severe pains has been modestly effective at best. ${ }^{8}$ Because of the refractory nature of these often unrelenting and excruciating pains to pharmacological management, particularly the below-level pains, the neurosurgical community historically performed the surgical intervention of spinal cord transection (cordectomy) in the SCI population to eliminate the possibility of any neuronal pain transmission to the brain from spinal cord caudal to the level of injury. Unfortunately, spinal cord transection did not effectively treat these below-level pains, and the practice was ultimately abandoned., ${ }^{3,14,17}$ These results supported the concept that SCI below-level central pain originates from spinal cord at or cephalad to the level

ABBREVIATIONS ASIA = American Spinal Injury Association; CNS = central nervous system; DREZ = dorsal root entry zone; FFT = fast Fourier transform; IML = intermediolateral; RMS = root mean square; $\mathrm{SCl}$ = spinal cord injury; SNS = sympathetic nervous system.

SUBMITTED March 27, 2017. ACCEPTED September 19, 2017.

INCLUDE WHEN CITING Published online March 2, 2018; DOI: 10.3171/2017.9.SPINE17373. 
of injury and/or from the brain, but not caudal to the level of injury. Other reports supported the same concept?

Similar thinking has led to the focus of dorsal root entry zone (DREZ) microcoagulation of the posterior gray matter of the spinal cord in regions at and cephalad to the level of injury in treating SCI neuropathic pain. Reported outcomes with an empirical technique of DREZ microcoagulation have been modest, with one large series showing that at-level pain responded best $(74 \%$ good results) and below-level pain responded poorly (20\% good results). ${ }^{9,12,13}$ One report employing a directed technique using electrical intramedullary guidance of DREZ neuronal hyperactivity showed much improved outcomes for both at-level and below-level pains, ${ }^{4}$ with another from our program confirming these outcomes and additionally proposing a sympathetic nervous system (SNS) mediation of below-level pain corresponding to a somatotopic map of neuronal hyperactivity of the DREZ and body regions of perceived pain. ${ }^{6}$

To demonstrate the potential of spinal cord caudal to the level of SCI to be a generator of below-level central pain, SNS mediation of such pains, and to help validate our somatotopic map of SCI below-level DREZ pain generators, we looked for and identified 3 unique patients in our normal course of treating those with SCI neuropathic pain with DREZ microcoagulation. These 3 patients had undergone prior surgeries to their spinal cords, cephalad to the levels of their injuries, in failed attempts at relieving their below-level central pains, and they had both imaging and visual confirmation of complete spinal cord transection at their levels of injuries as well as severe and intractable below-level central pain.

We report the results of DREZ microcoagulation performed entirely caudal to regions of complete traumatic spinal cord transection in these 3 unique patients, using electrical intramedullary guidance, to relieve SCI belowlevel central pain. We discuss implications regarding SNS mediation of below-level central pain as well as corroboration of a unique somatotopic map of below-level DREZ pain generators.

\section{Methods \\ Patient Population}

The 3 patients in this study were aged 49,54 , and 45 years at the time of treatment. All were men who had sustained thoracic SCIs, and all experienced severe belowlevel neuropathic pain (Fig. 1). The intervals between their injury and their first experience of below-level neuropathic pain were 19 years, 2 months, and 2 months. The time to surgery from onset of significant below-level pain was 2 years, 8 years, and 13 years, respectively. Descriptors characterizing the pains were "sharp," "burning," and "electrical" (Table 1). All 3 patients had undergone previous surgery to the spinal cord. One of the 3 patients had undergone previous spinal cord untethering surgery with expansion duraplasty and cyst shunting, in a failed attempt to alleviate his below-level pain. The other 2 patients had previously undergone DREZ microcoagulation at and cephalad to the level of injury in an attempt to alleviate SCI at-level and below-level neuropathic pain, achieving complete re- lief only of at-level pain. None of the procedures produced long-term below-level pain relief. All 3 patients were noted to have essentially complete traumatic spinal cord transections at the injury site, visually confirmed during the previous surgeries to the spinal cords described above. During these surgeries, a thin band of avascular scar found at the injury site replacing normal cord tissue, was transected, resulting in visually clear and separate ascending and descending portions of the spinal cord (Fig. 2). Four or more months subsequent to these prior surgeries, all 3 patients underwent DREZ microcoagulation to the spinal cord, caudal to the region of spinal cord transection at the injury site, to treat below-level pain. DREZ microcoagulation was guided by intraoperative electrophysiological monitoring of the DREZ for electrical hyperactivity.

\section{Preoperative Pain and Pain Therapies}

All 3 patients experienced continuous pain with bursts in intensity occurring multiple times daily. Pain was exacerbated by any noxious stimulus to the body, such as a skin sore or urinary tract infection. Pain occurred in regions of the body in which sensation was absent to testing. All 3 patients rated their pain as a 10 on a scale of $1-10$, with 10 considered near suicidal-level pain.

All patients underwent preoperative plain radiography, CT scanning, and MRI to evaluate the spine and spinal cord. Any patient with suicidal ideation underwent preoperative psychological evaluation and received clearance. Preoperatively all patients had undergone extensive pharmacological treatment, including administration of oral antidepressant, antiseizure, and narcotic medications. In general, these medications were considered ineffective, although 1 patient said that they "took the edge off."

\section{DREZ Recording Technique}

Spontaneous Neuroelectrical Activity

The methods of DREZ recording used in this study were described in a previous publication. ${ }^{6}$ Multilevel laminectomies were performed to expose the spinal cord at the injury site and level of spinal cord transection, as well as all spinal cord regions more caudal, to the level of the conus medullaris. Seven to 8 laminectomies were performed in each of the 3 patients. Spinal levels were determined by intraoperative radiological evaluation or knowledge of levels of existing spinal instrumentation. Intraoperative ultrasonography was used to identify the level of SCI and region of spinal cord transection. The dura mater was opened and the DREZs were identified using microscopic technique. Electrophysiological analyses of the DREZs were then performed from the injury site to the tip of the conus medullaris. To conduct such analyses, an active electrode was inserted into the specific DREZ. The active electrode was a $25-\mathrm{mm}$ monopolar electrode (model MF 25; TECA Corp.) with the distal $2 \mathrm{~mm}$ exposed. The electrode was implanted "freehand" in the DREZ with use of the intraoperative microscope to a $2-\mathrm{mm}$ depth. The axis of implantation was approximately $35^{\circ}$ to $45^{\circ}$ medially and was the same axis used for DREZ microcoagulation. Ground and reference Grass subdermal electroencephalographic electrodes were placed in exposed paraspinous 

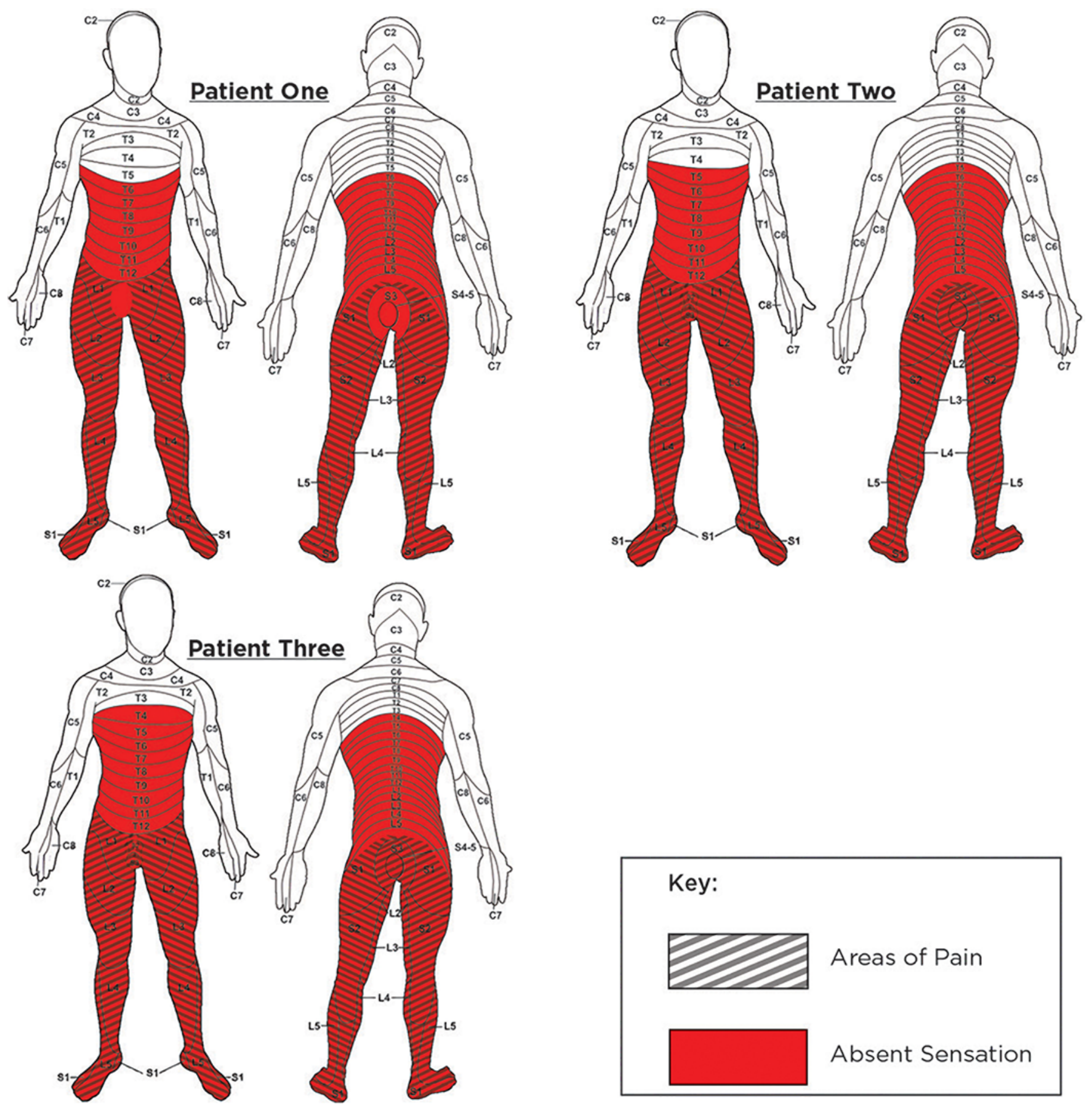

FIG. 1. Preoperative sensory chart and regions of perceived below-level pain. Figure is available in color online only.

muscle bilaterally. Spontaneous electrophysiological recordings were obtained using an evoked potential averager (Cascade Pro 32 channel; Cadwell Industries) at a gain setting of 50 with the high-frequency filter set at $3 \mathrm{kHz}$ and the low-frequency filter set at $100 \mathrm{~Hz}$. The recordings were 1 second in duration.

\section{Data Analysis of Spontaneous Neuroelectrical Recordings}

Methods of data analysis used in this study were described in a previous publication. ${ }^{6}$ In brief, the initial data were analyzed by RMS (root mean square, expressed in microvolts), frequency and voltage in the waveform by FFT (fast Fourier transform), and area under the waveform curve (expressed in microvolt milliseconds). These same analyses were performed to test data subsequent to DREZ microcoagulation. Both RMS analysis and areaunder-the-waveform data provided a single numerical value of the recorded neuroelectrical energy. Analyses were performed using a subroutine in the Cadwell Cascade software. A phenomenon that we describe as "spin- 
TABLE 1. Patient demographic data, neurologic level, and pain history and description

\begin{tabular}{ccccl}
\hline $\begin{array}{c}\text { Case } \\
\text { No. }\end{array}$ & $\begin{array}{c}\text { (yrs), } \\
\text { Sex }\end{array}$ & $\begin{array}{c}\text { ASIA } \\
\text { Classification }\end{array}$ & $\begin{array}{c}\text { Duration } \\
\text { of Severe } \\
\text { Pain (yrs) }\end{array}$ & \multicolumn{1}{c}{ Pain Descriptors } \\
\hline 1 & $49, \mathrm{M}$ & T-5 A & 2 & Burning \\
\hline 2 & $54, \mathrm{M}$ & T-4 A & 8 & Burning \\
\hline 3 & $45, \mathrm{M}$ & T-3 A & 13 & $\begin{array}{c}\text { Burning, stabbing, electrical, } \\
\text { pins \& needles }\end{array}$ \\
\hline
\end{tabular}

dles" was examined by passing the initial data through a tight digital filter with a band pass of $65-100 \mathrm{~Hz}$. A visual count was made of the number of spindle bursts in the 1-second recording, excluding artifacts caused by cardiac electrical activity or electrode movement. With these analyses, 2 distinct electrophysiological DREZ activities were found, consistent with our previous study. Those activities showing lower voltage and frequencies, smaller area under the waveform curve, and fewer than 3 spindles were considered to be non-pain-producing DREZ activity (Fig. 3 ); those showing higher voltage and frequencies, greater area under the waveform curve, and 3 or more spindles were considered to be regions of abnormal pain-producing neuroelectrical hyperactivity (Fig. 4). Analyses were also performed subsequent to DREZ microcoagulation of regions of abnormal neuroelectrical hyperactivity. It is notable that values of diminished activity are even less than those consistent with non-pain-producing activity (Fig. 5).

\section{DREZ Lesioning Procedure}

DREZ microcoagulation was performed using a needletipped electrocautery (Covidien Force FX electrosurgical generator; Valleylab, Inc.) at a setting of 10 desiccate for a 1-second pulse, with $1 \mathrm{~mm}$ of separation in all DREZs



FIG. 2. Case 3. Sagittal T2-weighted MR image showing regions of spinal cord transection and regions of DREZ microcoagulation.

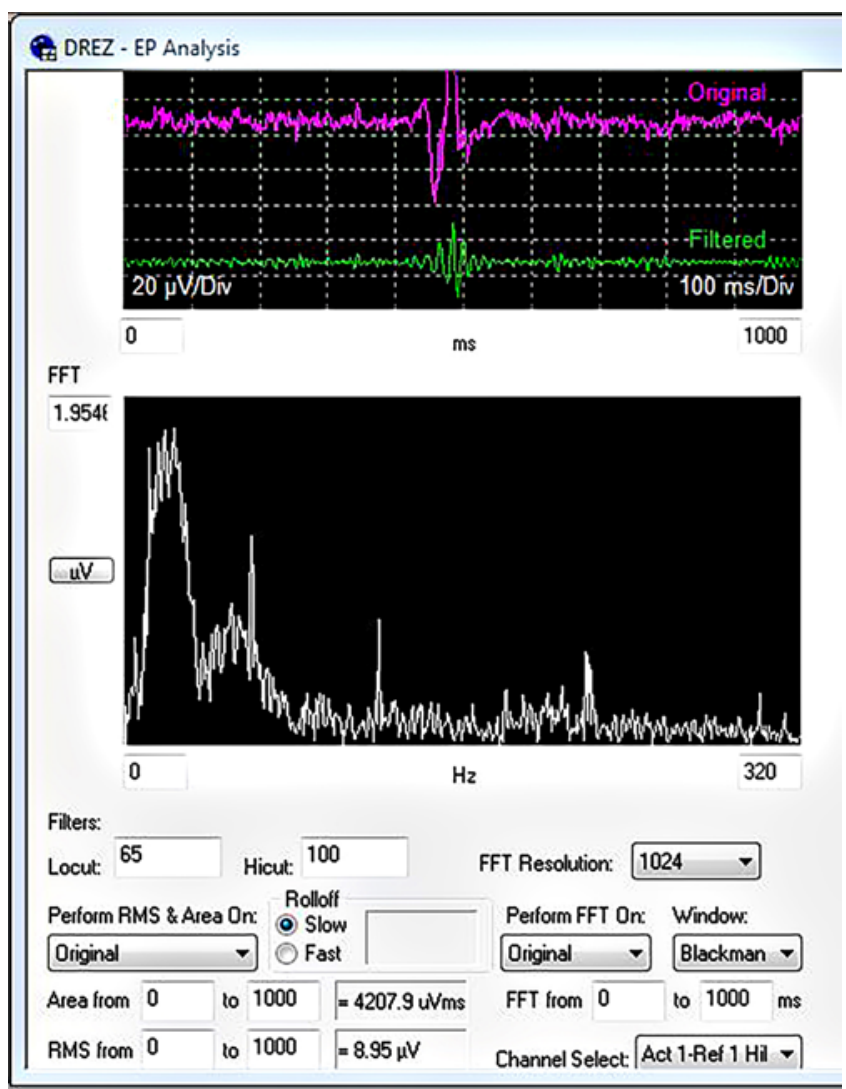

FIG. 3. Normal DREZ recording. Original unfiltered data, filtered data (spindles), and FFT labeled. Div = division; EP = evoked potential. Figure is available in color online only.

in which spontaneous neuroelectrical hyperactivity was demonstrated. Following microcoagulation, neuroelectrical hyperactivity was again measured. If recorded traces showed absence of neuroelectrical hyperactivity, no further lesions were made. If however, recorded traces continued to show spontaneous neuroelectrical hyperactivity, microlesioning was repeated.

\section{Results}

Complete or near-complete relief of all below-level neuropathic pains was achieved in all 3 patients; $100 \%$ pain relief was reported in the gluteal region, rectum, genitalia, upper leg, and lower leg and feet in all 3 patients, with the exception of residual burning and electrical sensations in the feet in 1 patient, rated $0-3$ out of 10 in intensity, and a nonpainful "tingling" and "warmth" sensation in the feet of another, rated 0-3 out of 10 in intensity ${ }^{16}$ (Fig. 6). Two of the 3 patients were able to completely wean off of all their preoperative pain medications which included Duragesic (fentanyl transdermal system) patch, Neurontin (gabapentin), and Cymbalta (duloxetine). The duration of postoperative follow-up (time to the most recent follow-up examination) in the 3 patients were $11 / 2,21 / 2$, and 11 years. Follow-up observation regarding pain relief was accomplished by telephone interview and outpatient evaluation. Pain was evaluated by means of a verbal scale in which scores of 1-10 indicated intensity of pain. 


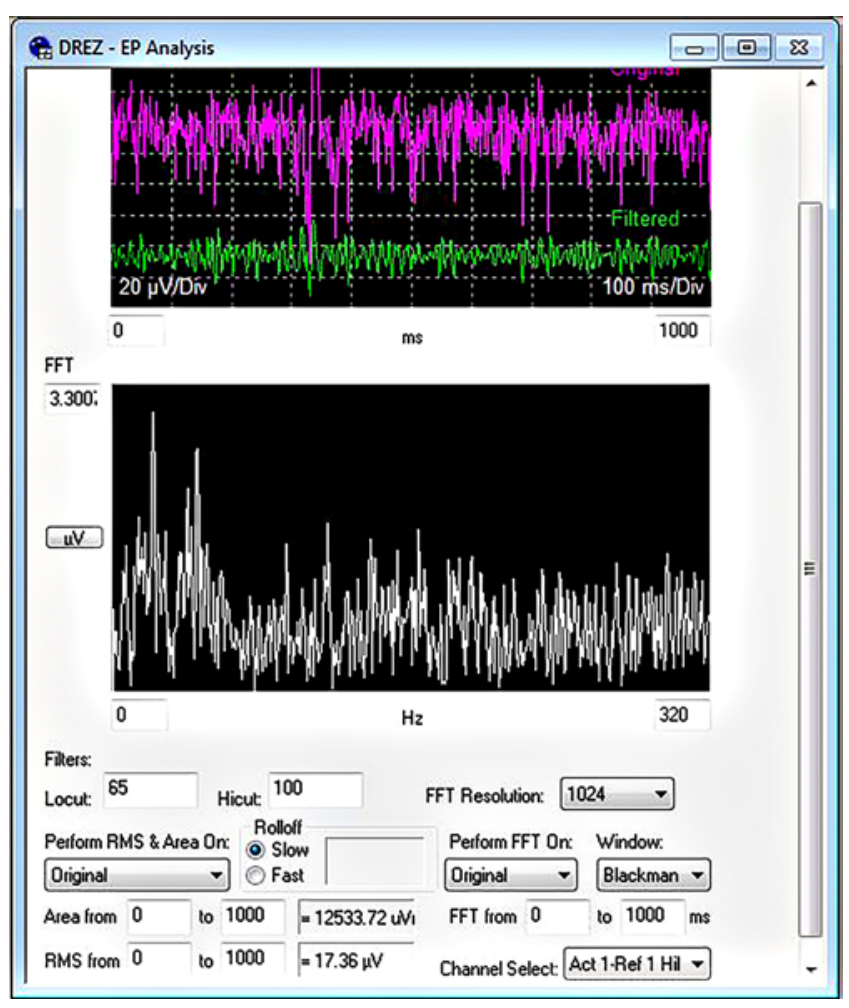

FIG. 4. Electrically hyperactive DREZ recording. Note increase in peakto-peak voltage of original recording, increase in spindles, and skewing of high electrical activity across frequency spectrum compared with Fig. 3 . Figure is available in color online only.

\section{Treatment-Related Morbidity}

All 3 patients underwent preoperative and postoperative American Spinal Injury Association (ASIA) sensory and motor testing. As anticipated, there were no changes in testing in these patients with ASIA A impairment with surgery only caudal to the injury site. There were no cases of wound infection, deep venous thrombosis, pulmonary embolus, cerebrospinal fluid leakage, or death. One patient developed a postoperative pseudomeningocele, which resolved without surgical treatment within 6 months of the DREZ microcoagulation procedure. At 10 months postoperatively, the same patient developed urosepsis with disc space infection and instability at L1-2 requiring surgical stabilization. At 3 years postoperatively, the same patient developed urosepsis with epidural abscess formation and instability at T-12/L-1, once again requiring stabilization. These episodes of instability were not considered treatment related. The reported level of pain reduction remained subsequent to these 2 surgeries.

\section{Classical and Nonclassical Somatotopic Mapping}

In our previous study, ${ }^{6}$ we suggested that perception of SCI below-level neuropathic pain followed a unique somatotopic map of DREZ hyperactivity and the corresponding sympathetic end organ supply from the spinal cord region containing the hyperactive DREZ. We proposed that DREZ hyperactivity in T3-T7 spinal cord regions will result in truncal below-level central pain, hyper-

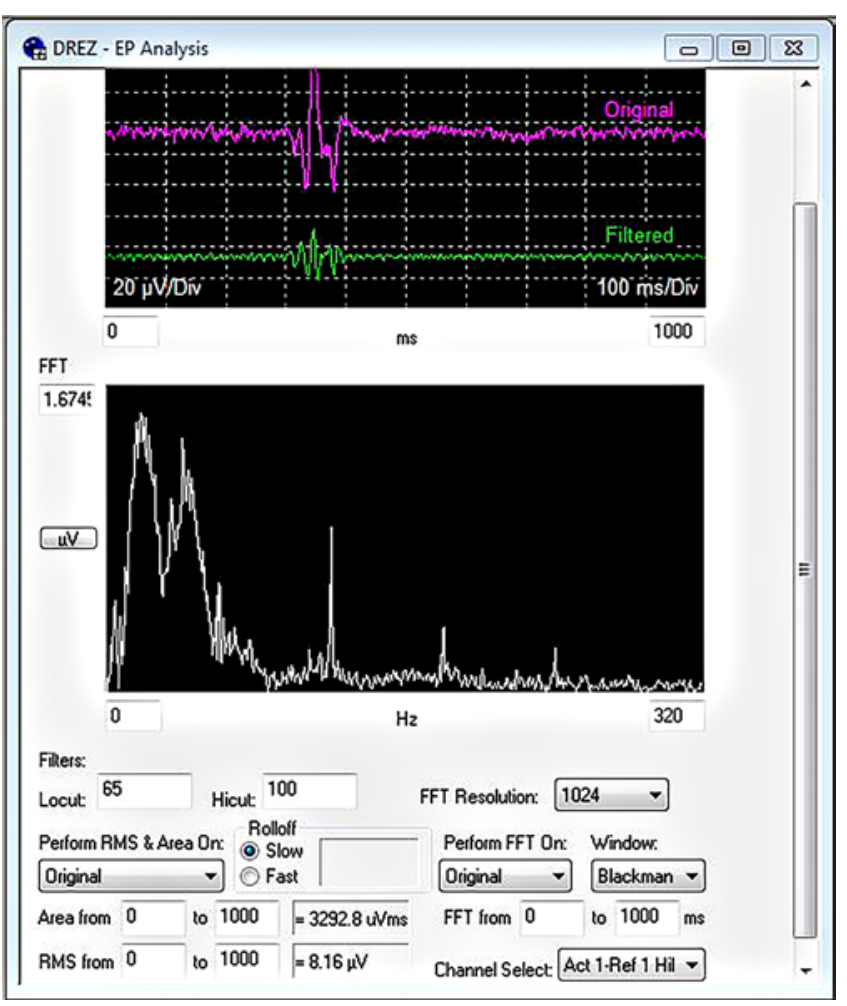

FIG. 5. Postmicrocoagulation DREZ recording. Note return of skewing of frequency plot toward lower frequencies and absence of spindles compared with Fig. 4. Figure is available in color online only.

activity in T8-T10 spinal cord regions, gluteal, rectal, and/ or genital region below-level pain, and hyperactivity in T11-L1 DREZs upper leg, lower leg, and foot below-level pain. All 3 patients in this study experienced upper leg, lower leg, and foot below-level pains and all 3 had DREZ electrical hyperactivity recorded in T11-L1 DREZs consistent with our previously reported somatotopic map of DREZ hyperactivity mediating pain from these body regions. Interestingly, all 3 patients also had DREZ hyperactivity recorded in more traditional DREZs of sensory rootlets subtending classical somatic pain for these same body regions (i.e., L1-S1) (Table 2).

Two of the 3 patients experienced below-level gluteal, rectal, and genital region pains and both had DREZ hyperactivity recorded in T-10 DREZs consistent with our previously reported somatotopic map. Interestingly both also had DREZ electrical hyperactivity recorded in the more traditional DREZ of sensory rootlets subtending classical somatic pain from these regions (i.e., S-2) (Table 2).

\section{Discussion}

Spinal cord injury neuropathic pains, both at level and more so below level, are very difficult to treat from both a pharmacological and surgical perspective. Greater understanding of the mechanism of pain generation subsequent to SCI is needed to improve outcomes achieved with these treatment modalities. We believe the data from this study have significantly added to this understanding. In our previous study, we demonstrated that electrical intramedullary 

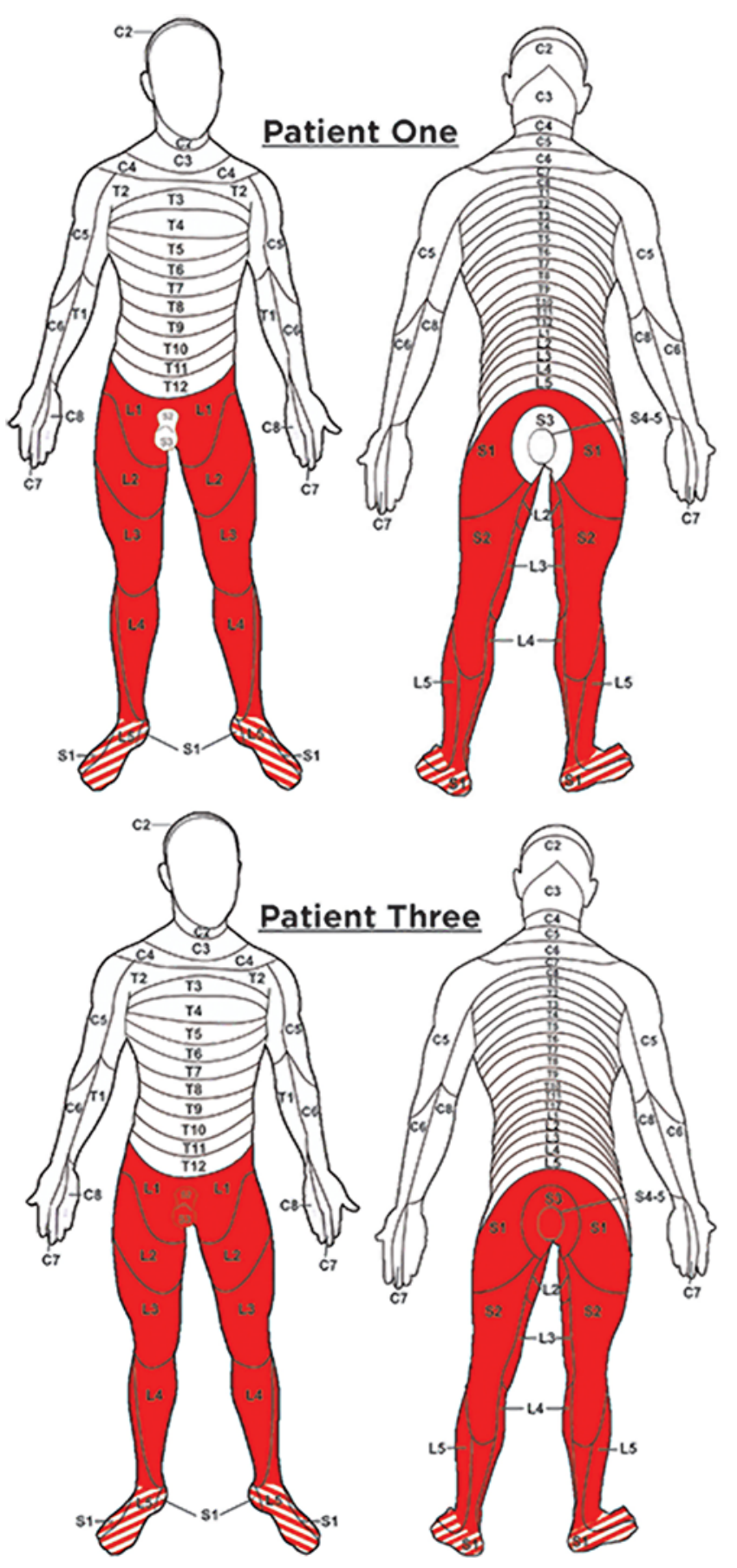

FIG. 6. Postoperative regions of pain relief. Figure is available in color online only.

guidance of DREZ lesioning, at and cephalad to the level of injury, in patients with pain secondary to SCI, substantially improves pain outcomes compared with an empirical technique. In that study, we also proposed a mechanism for SCI below-level neuropathic pain. We presented data showing that C-fiber deafferentation from SCI can lead to the development of spontaneous neuroelectrical hyperactivity in the spinal cord DREZ, approximating Rexed layers 1-3, and subsequent SCI neuropathic pain. With regard to below-level pain, we showed the strong correlation of

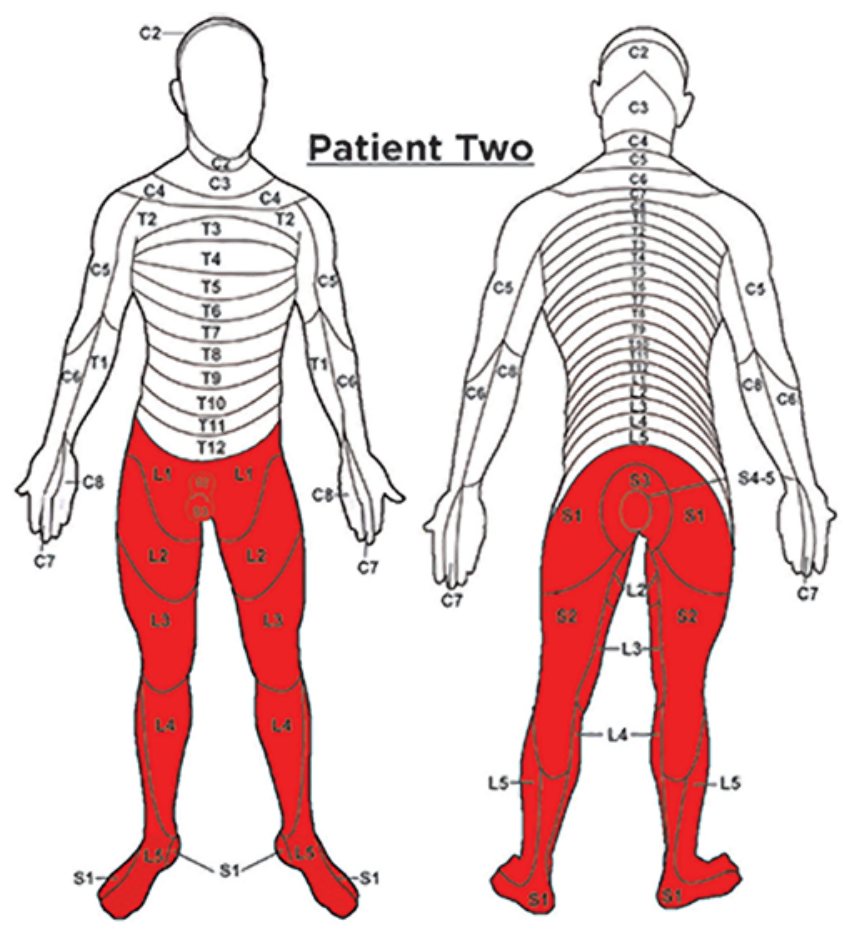

Key:



$70 \%$ Relief of Pain

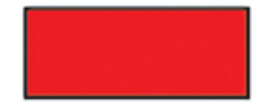

$100 \%$ Relief of Pain specific spinal cord levels of DREZ hyperactivity and intermediolateral (IML) cell column end organ innervation of specific body regions of perceived below-level pain and presented a somatotopic spinal cord map of SCI below-level DREZ pain generators. We suggested that mediation of DREZ hyperactivity through classical pain pathways (e.g., spinothalamic system) leads to at-level pain and that if the hyperactivity is mediated wholly or in part through the sympathetic nervous system, then pain will be perceived below-level, in regions described by our somatotopic map. 
TABLE 2. Intraoperative DREZ hyperactivity by case

\begin{tabular}{cccc}
\hline Level & Case 1 & Case 2 & Case 3 \\
\hline T-10 & & $\mathrm{X}$ & $\mathrm{X}$ \\
\hline T-11 & $\mathrm{X}$ & $\mathrm{X}$ & $\mathrm{X}$ \\
\hline T-12 & $\mathrm{X}$ & $\mathrm{X}$ & $\mathrm{X}$ \\
\hline L-1 & $\mathrm{X}$ & $\mathrm{X}$ & $\mathrm{X}$ \\
\hline L-2 & $\mathrm{X}$ & $\mathrm{X}$ & $\mathrm{X}$ \\
\hline L-3 & $\mathrm{X}$ & $\mathrm{X}$ & $\mathrm{X}$ \\
\hline L-4 & $\mathrm{X}$ & $\mathrm{X}$ & $\mathrm{X}$ \\
\hline L-5 & $\mathrm{X}$ & $\mathrm{X}$ & $\mathrm{X}$ \\
\hline S-1 & $\mathrm{X}$ & $\mathrm{X}$ & $\mathrm{X}$ \\
\hline S-2 & & $\mathrm{X}$ & $\mathrm{X}$ \\
\hline
\end{tabular}

Subsequent to that study, which involved patients who almost all had low thoracic and conus injuries, we continued with our historical success rate in treatment of belowlevel pain (complete or near-complete pain relief in $85 \%$ of cases), but only for those with low thoracic and conus injuries. As we accumulated more patients with midthoracic and upper thoracic injuries, we found our success rate in treating below-level pain greatly diminished in this subset of patients. Bolstered with our new insight for the potential of DREZ neuronal hyperactivity to use afferent SNS pathways, either directly ascending the cord to reach brain centers, and/or routing around the injury site by way of the sympathetic chain to do the same, we began and have continued to routinely investigate and address the spinal cord both cephalad and caudal to the level of injury with DREZ electrical recordings and microcoagulation in all cases of below-level SCI neuropathic pain. In doing so, we were able to maintain our historical success rate for essentially all levels of lumbar and thoracic SCIs. A report of this experience is forthcoming. But for this study, it was our desire to demonstrate that spinal cord and electrically hyperactive DREZs, caudal to the level of SCI, can be a sole source of below-level neuropathic pain, requiring the sympathetic chain, and thus the SNS, for transmission to brain pain centers. Additionally, confidence in the usefulness of our previously developed somatotopic map of DREZ hyperactivity and perceived SCI below-level neuropathic pain would be gained. If the strong correlation of the map to IML cell column innervation of end organs in body regions of perceived pain is mechanistically relevant, suggesting SNS involvement, then spinal cord transection at the injury site should fail to relieve below-level SCI neuropathic pain. With transection, pain transmission from spinal cord regions caudal to the level of injury would be able to route around the injury site via the sympathetic chain and reach brain centers. Thus, identification of patients with SCI below-level neuropathic pain and irrefutable evidence of complete spinal cord transection at the level of injury was required. Additionally, demonstration of complete or nearcomplete pain relief after DREZ microcoagulation of the spinal cord in regions only caudal to the level of transection needed to be achieved. In our routine course of treating patients with SCI below-level neuropathic pain with DREZ microcoagulation both cephalad and caudal to the level of injury, we were able to identify and treat 3 such patients with both sensory/motor complete clinical presentations and complete spinal cord transection visually confirmed at a prior surgery to the spinal cord. All 3 patients achieved $100 \%$ relief of all body regions of perceived below-level pain with the exception of minor residual painful or nonpainful sensations in only the feet of 2 patients, rated $0-3$ of 10 , with follow-up ranging from $11 / 2$ to 11 years. Two of the 3 patients were able to completely wean off of their narcotic, antiseizure, and antidepressant medications.

The patient outcomes reported in the current study are the first demonstrations that spinal cord caudal to the level of a completely transected spinal cord can be a source of below-level SCI neuropathic pain, and with regard to the patients of this study, essentially a sole source. Long-term follow-up to 11 years is supportive. Additionally we believe these outcomes are a first demonstration that below-level SCI neuropathic pain transmission can be substantially through the sympathetic chain and SNS-mediated pain pathways. To reach supraspinal pain centers, a new neuronal circuit must form postinjury, perhaps through reactive C-fiber sprouting, between hyperactive DREZs caudal to the level of spinal cord transection, and the sympathetic chain and spinal cord regions more cephalad to the transection, and/or the brain directly through the sympathetic chain and then occipital foramen. Transmission of DREZ hyperactivity through this new circuit may occur through ventral roots to the sympathetic chain, or in a retrograde fashion through dorsal roots to the sympathetic chain, with reentry into the spinal cord by way of ventral or dorsal roots (Fig. 7). Additional support of this proposed mechanism is the historical failure of cordectomy and cordotomy to relieve below-level SCI neuropathic pain, as well as our own personal experience with cordectomy.

The DREZ electrical data and pain outcome data acquired from this study supported, although it also required us to modify, our previously generated somatotopic map of below-level SCI neuropathic pain. In the construction of our previous map, we learned that hyperactive DREZs spanning from T-3 to L-1 were sufficient to generate neuropathic pain in all truncal regions, gluteal-rectal-genital regions, and the lower extremities. However, in this construction, electrical data acquired only cephalad to the level of SCI was used. The new caudal data from this study correlates DREZ hyperactivity corresponding to sensory rootlets subtending classical somatic body regions (i.e., L1-S2 for gluteal, rectal, genital, and lower-extremity pain) in addition to DREZ hyperactivity corresponding to IML cell column innervation of end organs in those same body regions (i.e., T8-L1 for gluteal, rectal, genital, lower-extremity pain) (Table 2). Nevertheless, pain relief occurring with destruction of these classical electrically hyperactive DREZ regions located caudal to the level of spinal cord transection still implicates the SNS in mediation of transmission to the brain. For these hyperactive DREZs more caudal in location to the IML cell column and in cord regions of classical innervation, perhaps injury-induced neuronal sprouting allowed for communication to the sympathetic chain via ascension through posterior gray matter to cord regions containing the IML cell column, through ventral rootlets at the same level to the sympathetic chain via gray rami, or in a retrograde fashion at 


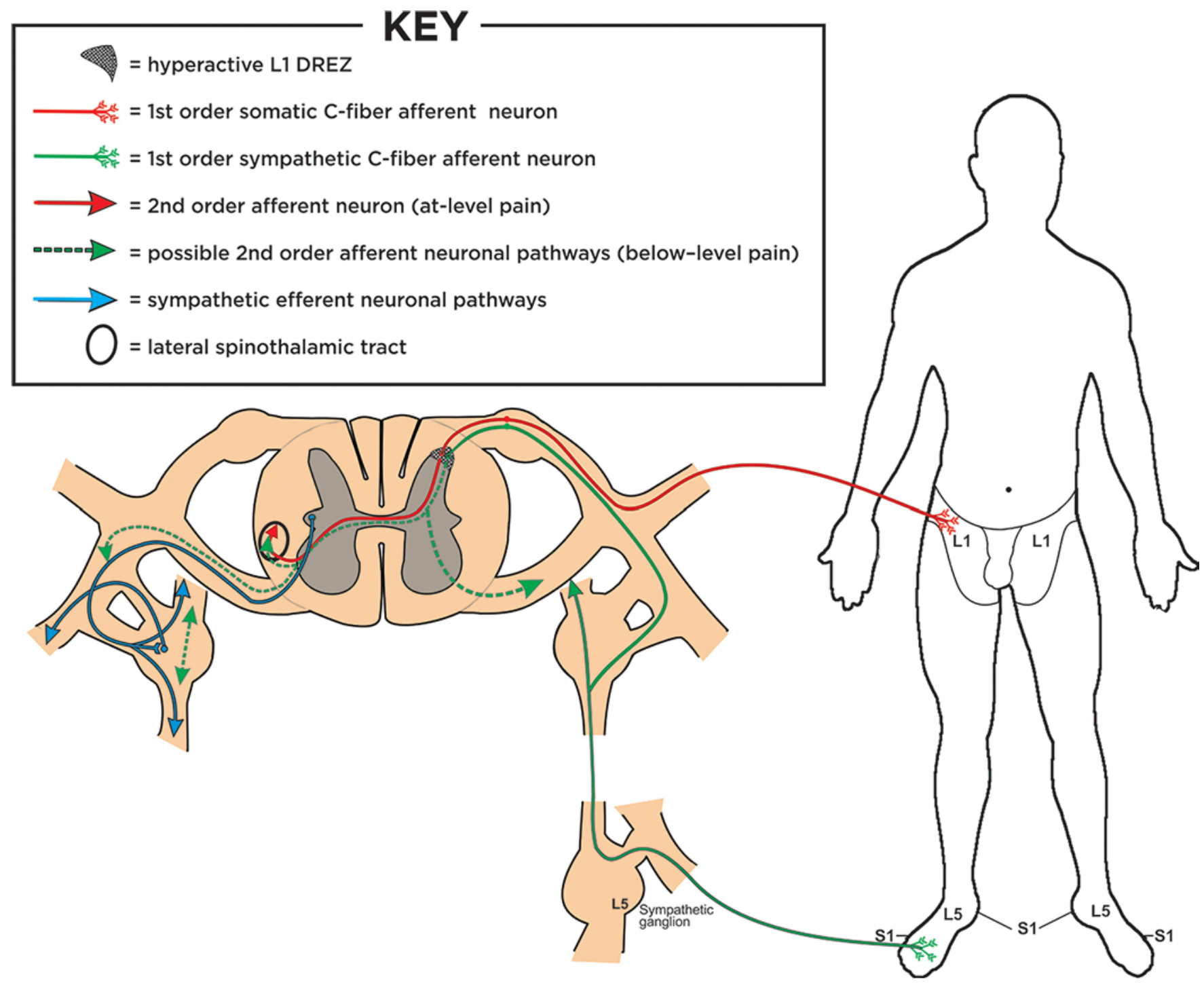

FIG. 7. The cross section represents the L-1 spinal cord at or immediately cephalad to the level of SCI in a patient with both at-level inguinal region and below-level foot pain and DREZ hyperactivity solely at L-1 (cross-hatched area). At-level somatic C-fiber afferents coursing from the inguinal region and below-level sympathetic $\mathrm{C}$-fiber afferents coursing from the foot are shown converging on the same L-1 DREZ. Note similarities of proposed second-order sympathetic afferent pathways to sympathetic efferent pathways. Note how transection of the spinal cord cephalad to the L-1 level could arrest at-level pain transmission to the supraspinal centers, but not below-level pain transmission. Figure is available in color online only.

the same level through sensory rootlets and DRGs to the sympathetic chain via gray rami.

We considered simply performing bilateral surgical sympathectomies in these 3 patients with complete cord transection, to eliminate transmission of all DREZ neuronal hyperactivity ascending to brain pain centers, to both treat their pain and demonstrate a SNS pathway. We abandoned the idea for concern about the extent of bilateral sympathetic chain resection or ablation required to achieve this outcome and the possible negative effects of sympathectomy on blood pressure control, bowel motility, hyperhidrosis, and creation of new neuropathic pain, all significant issues in the SCI population. The pharmacological equivalent requiring chronic dampening of all ascending sympathetic afferent neuronal transmission through the sympathetic chain is not available.
We recognize the limitations of this study with regard to its very small patient number as well as the difficulty in accumulating significant patient numbers to generate a much larger and more compelling study. Contusion, of course, is most commonly encountered in SCI, and in chronic states, even severe cord atrophy is seen. Irrefutably verifiable $100 \%$ spinal cord transection, however, is a rare occurrence, evidenced by our identifying only 3 such patients over approximately 15 years. Acknowledging these limitations, we turned to animal modeling to further explore the concept of sympathetically mediated SCI central pain. Animal modeling, of course, has its own issues, in that behavioral response (e.g., hind-paw withdrawal) rather than verbal response is required to assess pain relief. To eliminate transmission of neuronal hyperactivity of pain-generating DREZs to brain pain centers in such a 
model, all ascending SNS afferents, which are believed to travel through both the spinal cord and sympathetic chain, would have to be eliminated with both cord transection and bilateral sympathectomy. Doing this would eliminate the ability to assess a behavioral response. We therefore created a rat model of SCI below-level pain, completely sparing motor function and based on our human somatotopic map of below-level sympathetically mediated DREZ pain generators. In this model, injury solely to the DREZs and posterior gray matter of rats at the most caudal aspect of spinal cord containing the IML cell column (i.e., T-13/L-1), by way of sensory rootlet avulsion, a maneuver known to generate neuronal hyperactivity of the avulsed DREZ, resulted in predicted hind-paw allodynia, consistent with our human somatotopic map of DREZ pain generators (i.e., T-12/L-1), causing lower leg and foot pain. ${ }^{20}$ Although this unique rodent model of SCI below-level central pain is compelling, it does not definitively demonstrate SNS mediation. To do so, DREZ neuronal hyperactivity localized to those DREZ regions of rat cord must be identified (of which we have limited data) as well as corresponding neuronal hyperactivity in "sympathetic" brain centers that do not abate with spinal cord transection alone but do with both cord transection and sympathectomy or sympathectomy alone. If such phenomena were demonstrated, it could be reasonably inferred that neuronal transmission of DREZ hyperactivity occurred wholly or in part through the sympathetic chain to reach such brain centers. This work is currently underway.

\section{Conclusions}

Data from this study lead us to the following conclusions regarding the development of SCI below-level central pain in the paraplegic population: 1) The spinal cord DREZ caudal to the level of SCI can be a primary generator of SCI below-level central pain. 2) Neuronal transmission from a DREZ that generates SCI below-level central pain to brain pain centers can be primarily through SNS pathways. 3) Perceived SCI below-level central pain follows a unique somatotopic map of DREZ pain generators.

\section{References}

1. Bryce T, Ragnarsson K: Epidemiology and classification of pain after spinal cord injury. Top Sinal Cord Inj Rehabil 7:1-17, 2001

2. Davis L, Martin J: Studies upon spinal cord injuries; the nature and treatment of pain. J Neurosurg 4:483-491, 1947

3. Durward QJ, Rice GP, Ball MJ, Gilbert JJ, Kaufmann JCE: Selective spinal cordectomy: clinicopathological correlation. J Neurosurg 56:359-367, 1982

4. Edgar RE, Best LG, Quail PA, Obert AD: Computer-assisted DREZ microcoagulation: posttraumatic spinal deafferentation pain. J Spinal Disord 6:48-56, 1993

5. Eide PK: Pathophysiological mechanisms of central neuropathic pain after spinal cord injury. Spinal Cord 36:601612, 1998

6. Falci S, Best L, Bayles R, Lammertse D, Starnes C: Dorsal root entry zone microcoagulation for spinal cord injuryrelated central pain: operative intramedullary electrophysiological guidance and clinical outcome. J Neurosurg 97 (2 Suppl):193-200, 2002

7. Finnerup NB, Baastrup C: Spinal cord injury pain: mecha- nisms and management. Curr Pain Headache Rep 16:207216, 2012

8. Finnerup NB, Sindrup SH, Jensen TS: The evidence for pharmacological treatment of neuropathic pain. Pain 150:573581,2010

9. Friedman AH, Nashold BS Jr: DREZ lesions for relief of pain related to spinal cord injury. J Neurosurg 65:465-469, 1986

10. Ishijima B, Shimoji K, Shimizu H, Takahashi H, Suzuki I: Lesions of spinal and trigeminal dorsal root entry zone for deafferentation pain. Experience of 35 cases. Appl Neurophysiol 51:175-187, 1988

11. Melzack R, Loeser JD: Phantom body pain in paraplegics: evidence for a central "pattern generating mechanism" for pain. Pain 4:195-210, 1978

12. Rath SA, Braun V, Soliman N, Antoniadis G, Richter HP: Results of DREZ coagulations for pain related to plexus lesions, spinal cord injuries and postherpetic neuralgia. Acta Neurochir (Wien) 138:364-369, 1996

13. Rath SA, Seitz K, Soliman N, Kahamba JF, Antoniadis G, Richter HP: DREZ coagulations for deafferentation pain related to spinal and peripheral nerve lesions: indication and results of 79 consecutive procedures. Stereotact Funct Neurosurg 68:161-167, 1997

14. Ravenscroft A, Ahmed YS, Burnside IG: Chronic pain after spinal cord injury: a survey of practice in UK spinal injury units. Spinal Cord 37:25-28, 1999

15. Richards JS, Meredith RL, Nepomuceno C, Fine PR, Bennett G: Psycho-social aspects of chronic pain in spinal cord injury. Pain 8:355-366, 1980

16. Schlender $\mathrm{S}$ : New surgical techniques help relieve pain from spinal injury. Voice of America News. October 28, 2016. (http://www.voanews.com/a/new-surgical-techniques-helprelieve-pain-from-spinal-injury/3569670.html) [Accessed November 8, 2017]

17. Siddall PJ: Management of neuropathic pain following spinal cord injury: now and in the future. Spinal Cord 47:352-359, 2009

18. Siddall PJ, Loeser JD: Pain following spinal cord injury. Spinal Cord 39:63-73, 2001

19. Störmer S, Gerner HJ, Grüninger W, Metzmacher K, Föllinger S, Wienke C, et al: Chronic pain/dysaesthesiae in spinal cord injury patients: results of a multicentre study. Spinal Cord 35:446-455, 1997

20. Wieseler J, Ellis AL, McFadden A, Brown K, Starnes C, Maier SF, et al: Below level central pain induced by discrete dorsal spinal cord injury. J Neurotrauma 27:1697-1707, 2010

21. Woolsey RM: Chronic pain following spinal cord injury. J Am Paraplegia Soc 9:39-41, 1986

22. Yezierski RP: Pain following spinal cord injury: the clinical problem and experimental studies. Pain 68:185-194, 1996

\section{Disclosures}

The authors report no conflict of interest concerning the materials or methods used in this study or the findings specified in this paper.

\section{Author Contributions}

Conception and design: Falci. Acquisition of data: Falci, Indeck. Analysis and interpretation of data: Falci, Barnkow. Drafting the article: Falci. Critically revising the article: Falci. Reviewed submitted version of manuscript: Falci. Approved the final version of the manuscript on behalf of all authors: Falci. Administrative/ technical/material support: Indeck. Study supervision: Falci.

\section{Correspondence}

Scott Falci: Craig Hospital, Englewood, CO. spfalci@comcast.net. 